\title{
POTENSI KEMBANG SUSUT TANAH EKSPANSIF DI WILAYAH SOLO RAYA (STUDI KASUS DI TRUCUK, PEDAN, DAN NOGOSARI)
}

\author{
Niken Silmi Surjandari ${ }^{1}$, Noegroho Djarwanti ${ }^{1}$, Yusep Muslih Purwana ${ }^{1}$, Bambang \\ Setiawan, Harya Dananjaya ${ }^{1}$, Brilian Budi Prakosa ${ }^{1}$, Siti Nurlita Fitri ${ }^{{ }^{1}}$ \\ 1)Program Studi Teknik Sipil, Universitas Sebelas Maret \\ Email : nikensilmisurjandari@staff.uns.ac.id; ymuslih@staff.uns.ac.id; noegroho_dj@staff.uns.ac.id; \\ bambangsetiawan@staff.uns.ac.id; dananjaya.harya@gmail.com \\ Corresponding author: sitinurlitafitri@staff.uns.ac.id
}

\begin{abstract}
Expansive soil has commonly found in several areas around infrastructure projects such as; highways, irrigation systems, buildings, and bridges. The behavior of expansive soils affects the strengths and durability of the upper structure. The main characteristic of expansive soil is the swell-shrinkage influenced by water content. Moreover, the negative trait harms the structure. For example, the cracks of the highway pavement and building wall and differential settlements in bridges abutment are the damage phenomena caused by expansive soil. The soil spread in several area near Surakarta residency namely Nogosari, Boyolali, Cawas Pedan, Klaten Regency, Bendosari Gentan, Sukoharjo and Purwodadi. Therefore, these areas have high vulnerability damage of Expansive soil. The study for determining and collecting data on the potential for shrinkage, which is a characteristic of expansive soil, is necessary conduct. This research aims to identify the swell-shrinkage potential in laboratory tests. The test had carried out with property index (water content and atterberg limit) following code standards (SNI and ASTM). The liquid limit values for the Trucuk, Padan, and Nogosari areas are 84,75\%, respectively; 73.56\% and 49.05\%. The plasticity index values for the Trucuk, Padan, and Nogosari regions are as follows: 66,97\%; 45,72\%; and 28,74\%. Activity (AC) values for the 3 Pedan, Trucuk, and Nogosari locations are as follows: 1,61; 1,67; and 1,28. The value results are based on laboratory tests output, were 3 locations in the Klaten area, namely Trucuk, Pedan, and Nogosari. In summary, the zones have high susceptibility area damage by expansive soil. The result of this study is expected to be preliminary mapping guidance surround the Surakarta Residency.
\end{abstract}

Keywords: expansive soil, swell- shrinkage, damage, Surakarta residency

\begin{abstract}
Abstrak
Tanah ekspansif banyak dijumpai di sekitar wilayah infrastruktur: jalan raya, jaringan irigasi, dan bangunan gedung. Hal ini berdampak terhadap kekuatan dan keawetan bangunan tersebut. Sifat tanah ekspansif adalah tanah akan mengembang saat kadar air tinggi (musim hujan) dan akan menyusut saat musim kemarau. Karakteristik ini akan merusak semua bangunan yang berdiri di tanah tersebut. Kerusakan berupa retakan yang masif dan dapat berakibat fatal, serta bangunan tidak akan berfungsi dengan normal. Wilayah sekitar Solo Raya (Karesidenan Surakarta) banyak dijumpai kerusakan tersebut terutama badan jalan dan pemukiman rumah tinggal, sebagai contoh di Nogosari, Kabupaten Boyolali; Cawas dan Pedan, Kabupaten Klaten; Bendosari dan Gentan; Kabupaten Sukoharjo dan daerah lainnya misal jalan raya Solo-Purwodadi. Infrastruktur jalan retak memanjang hingga terjadi kubangan yang besar, rumah tinggal miring, dan retak-retak pada bagian dinding dan lantai. Hal ini akan merugikan penggunanya, untuk itu perlu dilakukan identifikasi dan pendataan tentang potensi kembang susut yang merupakan ciri khas dari tanah ekspansif (mengembang). Penelitian ini akan melakukan identifikasi potensi mengembang dari tanah dasar dengan uji laboratorium. Adapun uji laboratorium adalah uji indeks properti sesuai dengan standar pengujian yang berlaku (SNI dan ASTM). Nilai batas cair daerah Trucuk, Padan, dan Nogosari berturut-turut sebagai berikut, 84,75\%; 73,56\% dan 49,05\%. Nilai indeks plastisitas daerah Trucuk, Padan, dan Nogosari berturut-turut sebagai berikut, 66,97\%; 45,72\%; dan 28,74\%. Nilai AC untuk 3 lokasi Pedan, Trucuk, dan Nogosari berturut-turut sebagai berikut: 1,61; 1,67; dan 1,28. Berdasarkan pengujian yang dilakukan terhadap 3 lokasi di daerah Klaten yaitu Trucuk, Pedan, dan Nogosari diperoleh kesimpulan bahwa tanah memiliki potensi pengembangan yang tinggi. Hasil riset ini diharapkan dapat memberikan informasi teknis tentang tanah ekspansif di wilayah Solo Raya, dan dapat digunakan sebagai pedoman pemetaan potensi tersebut.
\end{abstract}

Kata Kunci : Ekspansif, kembangsusut, kerusakan, Soloraya

\section{PENDAHULUAN}

Tanah ekspansif memberikan dampak yang tidak menguntungkan masyarakat selaku pengguna, baik berupa jalan raya, jaringan irigasi, bangunan gedung maupun pemukiman yaitu tentang kekuatan dan keawetan bangunannya. Sifat utama tanah ekspansif adalah memiliki potensi kembang susut pada fluktuasi kadar air yang tinggi, yaitu tanah akan mengembang saat kadar air tinggi saat musim hujan dan akan menyusut saat musim kemarau. Potensi kembangsusut ini akan merusak semua bangunan yang berdiri di tanah tersebut, kerusakan berupa retakan yang masif dan dapat berakibat fatal serta bangunan tidak akan berfungsi dengan normal. 
Wilayah sekitar Solo Raya (Karesidenan Surakarta) banyak dijumpai kerusakan tersebut, terutama badan jalan dan pemukiman rumah tinggal. Beberapa daerah yaitu di Nogosari, Kabupaten Boyolali; Cawas dan Pedan, Kabupaten Klaten; Bendosari dan Gentan, Kabupaten Sukoharjo; dan Jalan Solo-Purwodadi. Infrastruktur jalan retak memanjang hingga terjadi kubangan yang besar, dan rumah tinggal pun miring, retak-retak pada bagian dinding dan lantai. Hal ini akan merugikan penggunanya. Oleh karena itu, perlu dilakukan identifikasi dan pendataan tentang potensi kembang susut yang merupakan ciri khas dari tanah ekspansif (mengembang).

Faizul Chasanah (2015) melakukan analisis peningkatan jalan akibat kerusakan struktur perkerasan di atas tanah ekspansif pada ruas Jalan Purwodadi-Geyer. Rekomendasi yang dihasilkan dari penelitian adalah peningkatan jalan baik dengan bahan aspal maupun beton sebagai lapis tambah hanya bersifat sementara. Perlu ada kajian lebih lanjut untuk menemukan solusi yang paling tepat dalam mengatasi kerusakan jalan pada ruas jalan di atas tanah dasar ekspansif. Metode cakar ayam dan geomembrane vertikal bisa menjadi alternatif pilihan selanjutnya.

Febra Ndaru, dkk (2015) membuat penelitian dengan hasil rekomendasi penelitian adalah dengan penambahan bahan campuran berupa serbuk gypsum dan abu sekam padi, nilai specific gravity mengalami penurunan dibandingkan dengan tanah asli. Sedangkan untuk nilai liquid limit, indeks plastisitas mengalami penurunan dibandingkan dengan tanah asli, sedangkan untuk shrinkage limit dan plastic limit mengalami peningkatan.

Penelitian terkait tanah ekspansif sudah banyak dilakukan antara lain oleh Sutikno dan Budi Damianto (2009) melakukan uji stabilisasi tanah ekspansif dengan menggunakan bahan kapur untuk timbunan. Pengaruh kapur terhadap nilai CBR tanah ekspansif memberikan hasil positif yang signifikan. G.D. Pandulu dan Suhudi (2012) menyatakan bahwa pada pelaksanaan pembangunan jalan dibutuhkan abu sekam seberat 669 ton dari hasil pembakaran abu sekam padi. Penelitian ini dilakukan di kabupaten Probolinggo.

Syawal dkk (2016) melakukan penelitian dengan rekomendasi penelitian menyebutkan bahwa tanah lempung Glee Geunteng dengan campuran kapur menunjukkan peningkatan CBR dan menurunkan nilai pengembangan akan tetapi untuk penggunaan pada jalan kelas tinggi (I, II, atau III) tanpa dilakukan stabilisasi tidak direkomendasi karena kondisi tanah asli. Samuel Giovani, dkk (2018) membuat usulan perbaikan tanah ekspansif yang terletak di wilayah Surabaya Barat. Hasil penelitian merekomendasikan penggunaan geomembrane untuk perbaikan tanah ekspansif di perumahan Surabaya Barat. Berdasarkan penelitian yang dilakukan oleh U.G.Fulzele, V.R.Ghane, dan D.D.Parkhe (2016), tanah ekspansif sangat keras pada kondisi kering dan kehilangan kekuatannya saat basah; perilaku kembang susut dipengaruhi kandungan mineral montmorillonite dan illite; apabila akan digunakan pondasi tiang maka desainnya dipengaruhi oleh kondisi tanah dan beban dari struktur atas; metode penggantian tanah dapat dilakukan jika zona aktifnya tipis sehingga pondasi bangunan terletak di tanah keras; pembangunan sebuah proyek disarankan dilakukan saat musim kering.

Penelitian yang dilakukan oleh Chayan Gupta dan Ravi Kumar Sharma (2016) menghasilkan kesimpulan bahwa tanah ekspansif dapat distabilisasi dengan pasir pantai, fly ash, dan marble dust. Campuran material-material tersebut mengubah gradasi tanah ekspansif menjadi lebih baik. Stabilisasi tanah ekspansif dengan material-material tersebut telah sukses digunakan sebagai timbunan dan material subgrade pada perkerasan lentur dengan biaya yang lebih murah. S. Vinodhkumar, D. Ramya , dan P. Kulathaivel (2016) melakukan penelitian dengan hasil indeks plastisitas, indeks pengembangan, $\mathrm{pH}$, dan kapasitas pertukaran kation menurun dengan ditambah fly ash; sedangkan total soluble soil dan kandungan kalsium karbonat meningkat dengan penambahan fly ash.

\section{METODE}

Pada penelitian ini, tanah yang digunakan adalah tanah lempung plastisitas tinggi yang berasal dari daerah Pedan, Trucuk, dan Nogosari, Kabupaten Klaten, Jawa Tengah. Pengambilan tanah dilakukan dengan kondisi tanah terganggu (disturbed) secara manual menggunakan skop pada kedalaman lebih dari 0,2 $\mathrm{m}$ di bawah permukaan tanah. Area pengambilan sampel ditunjukan pada Gambar 1. 


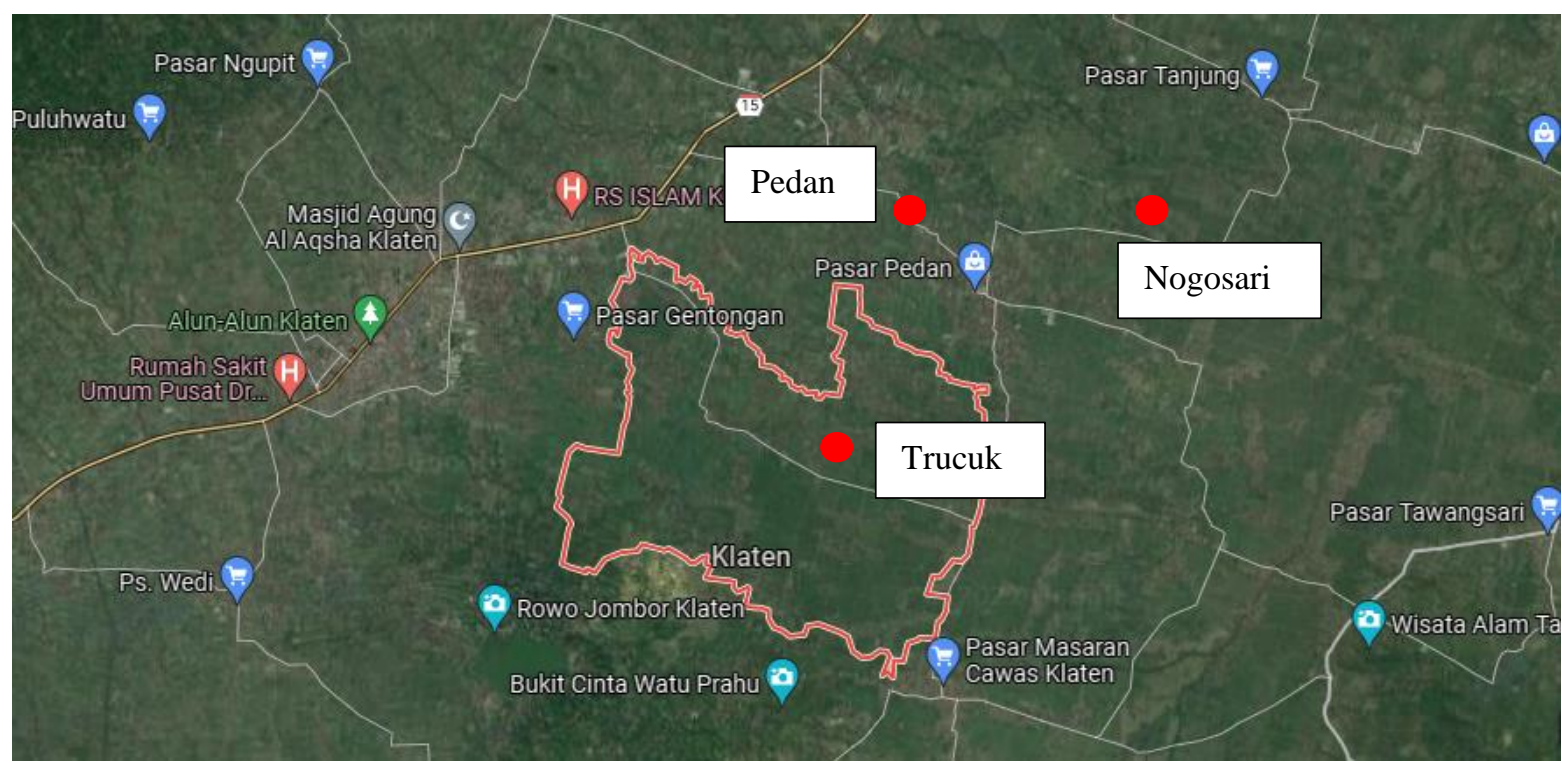

Gambar 1. 3 Titik pengambilan sampel

Gambar 1 menjelaskan daerah pengambilan sampel untuk penelitian ini. Setelah pengambilan sampel, tanah disturb tersebut dites di Laboratorium Mekanika Tanah Teknik Sipil UNS. Pengambilan contoh tanah dari lokasi tersebut didasarkan pada keluhan masyarakat akan adanya kerusakan infrastruktur di beberapa daerah yang mirip dengan karakteristik tanah ekspansif. Selain itu secara visual tanah dasar di beberapa lokasi juga mirip dengan tanah ekspansif.

Pengujian tanah dilakukan untuk mengetahui klasifikasi tanah dan indeks propertinya. Untuk mengetahui klasifikasi tanah dilakukan pengujian berupa specific gravity, analisis saringan, hidrometer, dan pengujian batas plastis dan batas cair. Acuan standar pengujian yang digunakan adalah ASTM.

Ekspansivitas tanah dapat dihubungkan dengan sifat plastisitas tanah sebagaimana ditunjukkan pada Tabel 1

Tabel 1. Korelasi indeks plastisitas, indeks susut dengan tingkat pengembangan

\begin{tabular}{lll}
\hline PI $\mathbf{( \% )}$ & SI $\mathbf{( \% )}$ & Degree of Ekspansion \\
\hline$<12$ & $<15$ & Low \\
$12-23$ & $15-30$ & Medium \\
$23-32$ & $30-40$ & High \\
$>32$ & $>40$ & Very High \\
\hline
\end{tabular}

(Chen, Raman ,1967, dalam Pd T-10-2005-B)

Batas atterberg dan fraksi lempung dapat dikombinasikan menjadi satu parameter yang dinamakan tingkat keaktifan (activity). Pada umumnya, tanah dengan indeks plastisitas (PI) kurang dari 15\% tidak akan memperlihatkan perilaku pengembangan. Untuk tanah dengan PI lebih besar dari 15\%, kadar lempung dan batas atterbergnya harus diuji. Persamaan 1 berikut untuk menentukan tingkat keaktifan suatu tanah.

$$
A_{c}=\frac{P I}{C F}
$$

\section{Keterangan :}

$\mathrm{A}_{\mathrm{c}}=$ tingkat keaktifan (tanpa satuan)

PI = indeks plastisitas $(\%)$

$\mathrm{CF}=$ persentase fraksi lempung $(\%)$

Jika dikorelasikan dengan potensi pengembangan, maka tanah lempung dibagi menjadi tiga kelas berdasarkan tingkat keaktifannya, seperti yang diperlihatkan pada Tabel 2 berikut 
Tabel 2. Korelasi tingkat keaktifan dengan potensi pengembangan

\begin{tabular}{lll}
\hline PI (\%) & SI (\%) & Degree of Ekspansion \\
\hline$<12$ & $<15$ & Low \\
$12-23$ & $15-30$ & Medium \\
$23-32$ & $30-40$ & High \\
$>32$ & $>40$ & Very High \\
\hline
\end{tabular}

(Skempton, 1953, dalam Pd T-10-2005-B)

Penelitian ini akan melakukan identifikasi deposit tanah ekspansif yang berada di sekitar wilayah Solo Raya dengan melakukan uji indeks properties di laboratorium.

\section{HASIL DAN PEMBAHASAN}

Pengujian indeks properti tanah adalah berat jenis tanah, kadar air tanah di lapangan, gradasi tanah, dan batas-batas plastisitas. Hasil lengkap pengujian disajikan di Tabel 3.

Tabel 3 Hasil pengujian indeks properties

\begin{tabular}{|c|c|c|c|c|c|c|c|c|c|c|}
\hline $\begin{array}{l}\text { Parameter } \\
\text { satuan }\end{array}$ & $\begin{array}{l}\text { wn } \\
\%\end{array}$ & $\begin{array}{l}\text { Gs } \\
- \\
\end{array}$ & $\begin{array}{l}\text { LL } \\
\%\end{array}$ & $\begin{array}{l}\text { PL } \\
\% \\
\end{array}$ & $\begin{array}{l}\text { PI } \\
\% \\
\end{array}$ & $\begin{array}{l}\text { SL } \\
\%\end{array}$ & $\begin{array}{l}\text { kerikil } \\
\%\end{array}$ & $\begin{array}{l}\text { pasir } \\
\%\end{array}$ & $\begin{array}{l}\text { lanau } \\
\%\end{array}$ & $\begin{array}{l}\text { lempung } \\
\%\end{array}$ \\
\hline Trucuk & 44,28 & 2,31 & 84,75 & 17,78 & 66,97 & 16,69 & 1,32 & 8,53 & 48,59 & 41,56 \\
\hline Pedan & 39,02 & 2,11 & 73,56 & 27,84 & 45,72 & 22,97 & 0,00 & 22,38 & 50,38 & 27,24 \\
\hline Nogosari & 51,76 & 2,45 & 49,05 & 20,31 & 28,74 & 21,30 & 0,02 & 11,33 & 66,34 & 22,31 \\
\hline
\end{tabular}

Hasil pengujian gradasi sampel Tanah Trucuk diperoleh nilai sebagai berikut:
1. Kerikil (gravel)
$=1,32 \%$
2. Pasir (sand)
$=8,53 \%$
3. Lanau dan Lempung
$=90,15 \%$

Hasil pengujian Batas-batas Atterberg sampel Tanah Trucuk diperoleh nilai sebagai berikut:

1. Batas cair (LL) = $=84,75 \%$

2. Indeks plastisitas $(\mathrm{PI}) \quad=66,97 \%$

Tanah diklasifikasi menurut sistem klasifikasi USCS yang dimodifikasi oleh ASTM. Sistem klasifikasi ini dibuat berdasarkan data distribusi ukuran butiran dan batas - batas konsistensi tanah. Tanah Trucuk termasuk dalam tanah berbutir halus disebabkan persentase yang lolos saringan nomor 200 lebih dari 50\% yaitu sebesar 90,15\%. Kemudian dari nilai indeks plastisitas dan batas cair diplot dalam grafik plastisitas Casagrande untuk menentukan jenis tanah. Berdasarkan diagram plastisitas Casagrande, tanah Trucuk termasuk dalam kelompok $\mathrm{CH}$ yaitu golongan $(\mathrm{CH})$ atau lempung dengan plastisitas tinggi. Dengan cara yang sama maka diperoleh klasifikasi tanah Pedan dan Nogosari berturut-turut adalah CH dan CL (lempung dengan plastisitas rendah).

Identifikasi sifat kembang susut tanah di lokasi pengambilan menggunakan data batas-batas Atterberg. Merujuk Tabel 1 yang menghubungkan derajat pengembangan dengan nilai indeks plastisitas tanah, maka 3 (tiga) lokasi pengambilan sampel memiliki nilai PI lebih besar dari 32 sehingga disimpulkan ketiga lokasi memiliki derajat pengembangan sangat tinggi. Uji pengembangan dilakukan untuk membandingkan dengan nilai awalnya untuk meneliti variasi perilaku pengembangan tanah ekspansif pada kedalaman yang berbeda setelah pengujian model selesai (She dkk, 2019). Beberapa cara untuk mengurangi tingkat aktivitas suatu mineral dalam ekspansive soil yaitu seperti penelitian yang dilakukan oleh (Alnmr \& Ray, 2021), penelitian tersebut menyajikan tinjauan perilaku pengembangan campuran pasir-lempung serta pengaruh pasir terhadap karakteristik fisik dan mekanik tanah ekspansif.

Tingkat keaktifan (Ac) tanah dihitung dengan Persamaan 1, kemudian hasilnya dihubungkan dengan Tabel 2. Hasil perhitungan memberikan nilai Ac untuk 3 lokasi Pedan, Trucuk, dan Nogosari berturut-turut adalah 1,61; 1,67; dan 1,28. Nilai-nilai tersebut mengindikasikan bahwa di tiga lokasi pengambilan sampel memiliki tingkat keaktifan yang termasuk kategori aktif dan potensi pengembangannya tinggi. Hasil penelitian ini diharapkan dapat memberi informasi awal pada bidang geoteknik untuk perencanaan konstruksi didaerah sekitar. Sehingga kerusakan akibat tanah ekspansif pada infrastruktur di atasnya dapat dikurangi. 


\section{SIMPULAN}

Dari hasil penelitian awal tentang potensi tanah ekspansif di beberapa lokasi di Solo Raya, maka dapat disimpulkan beberapa hal penting antara lain:

1. Klasifikasi sampel tanah Trucuk, Pedan, dan Nogosari berturut-turut adalah CH, CH, dan CL,

2. Nilai batas-batas Atterberg LL dan PI untuk Trucuk adalah 84,75; 66,97,

3. Nilai batas-batas Atterberg LL dan PI untuk Pedan adalah 73,$56 ; 45,72$,

4. Nilai batas-batas Atterberg LL dan PI untuk Nogosari adalah 49,05; 28,74,

5. Nilai Ac untuk Trucuk, Pedan, dan Nogosari berturut-turut adalah sebagai berikut adalah 1,61; 1,67; dan 1,28,

6. Berdasarkan pengujian yang dilakukan terhadap 3 lokasi di Kota Klaten yaitu Trucuk, Pedan, dan Nogosari diperoleh kesimpulan bahwa tanah memiliki potensi pengembangan yang tinggi.

\section{UCAPAN TERIMAKASIH}

Penelitian ini dibiayai oleh dana non APBN hibah skema Riset Grup dengan no kontrak 260/UN27.22/HK.07.00/2021 dari LPPM UNS. Untuk itu diucapkan terima kasih kepada pihak LPPM UNS

\section{REFERENSI}

Alnmr, A. and Ray, R. P., 2021, "Review of The Effect of Sand on The Behavior of Expansive Clayey Soils", Acta Technica Jaurinensis. doi: 10.14513/actatechjaur.00611.

Arifudin Nur, Suryo Hapsoro Tri Utomo, M. Zudhy Irawan, 2019, "Stabilisasi Tanah Ekspansif Menggunakan Kapur dan Spent Catalyst untuk Tanah Dasar Perkerasan”, Jurnal Transportasi. Vol. 19 No. 1 April 2019: 2130

Chen, F., 1975, "Foundation on Expansive Soils", Elseiver Scientific Publication Company, New York.

Sutikno dan Damianto, B., 2009, "Stabilisasi Tanah Ekspansif dengan Penambahan Kapur (Lime): Aplikasi pada Pekerjaan Timbunan", Jurnal Teknik Sipil dan Perencanaan, Vol. 11 No. 2, pp. 101 - 108

Gupta, C., S, Ravi Kumar, 2016, "Black Cotton Soil Modification by The Application of Waste Materials", Periodica Polytechnica Civil Engineering,.Vol. 60, No. 4, pp. 479-490.

Chasanah, F., 2015, “Analisis Peningkatan Jalan Akibat Kerusakan Struktur Perkerasan di Atas Tanah Ekspansif”, Jurnal Teknisia. Vol. 20 No. 1, pp. $12-21$.

W, Febra Ndaru., S, Eko Andi, Zaika, Y., Munawir A., \& Rachmansyah A., 2015, "Perbaikan Tanah Ekspansif dengan Penambahan Serbuk Gypsum dan Abu Sekam Padi untuk Mengurangi Kerusakana Struktur Perkerasan", Rekayasa Sipil. Vol. 9 No. 3 , pp. 251 - 256.

G.D.Pandulu \& Suhudi, 2012, "Peningkatan Kualitas Infrastruktur Jalan pada Tanah Ekspansif dengan Pemanfaatan Limbah Pertanian Guna Mendukung Pengembangan Wilayah", Buana Sains. Vol. 12 No. 1, pp. 123-130.

Hardiyatmo, H.C., 2017, "Mekanika Tanah 1", UGM Press, Yogyakarta.

Departemen Pekerjaan Umum, “ Pd T-10-2005-B: Penanganan Tanah Ekspansif untuk Konstruksi Jalan”, Departemen Pekerjaan Umum Rancangan Akhir RPJMD Kabupaten Klaten Tahun 2016-2021.

Giovani, S., Mochtar I. B., Mochtar N. E., 2018, "Usulan Penyelesaian Masalah Rekayasa Tanah untuk Jalan dan Gedung di Atas Tanah Ekspansif Studi Kasus Surabaya Barat”, Jurnal Teknik Sipil ITS, Vol. 7 No. 1, pp. F186 - F191.

She, J. et al., 2019, "Experimental Study on The Swelling Behavior of Expansive Soil at Different Depths Under Unidirectional Seepage", Applied Sciences (Switzerland), Vol. 9 No. 6. doi: 10.3390/app9061233.

Syawal, M. U., dan Saleh S. M., 2016, "Dampak Penambahan Kapur pada Tanah Lempung Ekspansif terhadap Nilai CBR Tanah Dasar Konstruksi Jalan”, Jurnal Teknik Sipil Universitas Syiah Kuala, Vol. 6 No. 1, September 2016, pp. $45-56$.

U.G. Fulzele, V.R. Ghane, D.D. Parkhe, 2016," Study of Structures in Black Cotton Soil", Proceedings of 64 th IRF International Conference, Pune, India, 16 October 2016, ISBN: 978-93-86291-14-1 .

S.Vinodhkumar, D.Ramya, P.Kulathaivel, 2016,"Index and Chemical Properties of Black Cotton Soil Blended With Fly Ash”, International Journal of Research in Advanced Technology (IJORAT). Vol. 1 No. 6. 